Nina Korać

korac.nina@gmail.com

UDK 61(091)

Izvorni naučni članak

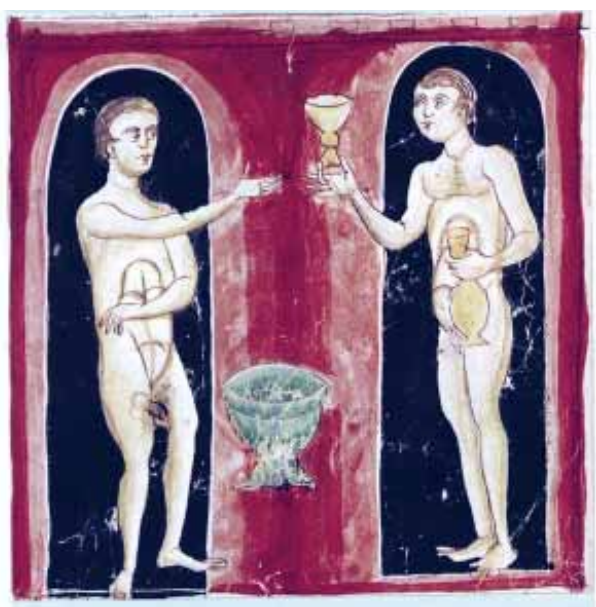

\title{
NEKI ASPEKTI ANTIČKE MEDICINE
}

\begin{abstract}
APSTRAKT
U radu je dat kratak pregled nekih aspekata antičke medicine. Antički, grčki i rimski, nagrobni spomenici i papirusi (papirus Ebers i drugi) dragoceni su dokumenti koji o tome svedoče. Briga za zdravlje stanovnika je bila na zavidnom nivou a tradicionalna narodna medicina je postojala paralelno sa stručnom lekarskom praksom. U gradovima su postojale apoteke gde su se kupovali lekovi iz mnogih udaljenih krajeva Rimskog carstva. Briga o zdravlju stanovnika glavnog grada Rima i kasnije Konstantinopolja, poverena je municipalnoj upravi. Iako su vojni lekari bili izdvojeni od civilnih, ponekad je dolazilo i do mešanja i to je bilo posebno kodifikovano (Codex Iustinianus). U Rimskom carstvu nisu postojale škole, kao što je to bio slučaj u Grčkoj ili na maloazijskoj obali. Antička medicina je bila podeljena na više oblasti: 1) Hirurgiju 2) Dijetetiku 3) Anatomiju 4) Fiziologiju 5) Farmakologiju 6) Ginekologiju i 7) Oftalmologiju.
\end{abstract}

\section{Ključne reči: rimska medicina, grčka medicina, Galen, Diokurid, Hipokrat, Plutarh, Diodor, KSENOFONT, INFEKCIJE, MELEMI, LEKovi, PARAPSTAE, CodeX IUSTINIANuS}

Egipat, kako se to jasno vidi iz Papyrus Ebers- $a$, je prostor gde se medicina prvi put značajno razvila. Činjenica je i da je savremena medicina nezamisliva bez utemeljenja u lekarskim školama Grčke, ali je još značajnije da je to jedna od retkih disciplina koju su Rimljani uzdigli na nivo koji je prevaziđen tek u novom dobu. Oni su unapredili ne samo medicinu kao uskostručnu delatnost, već i javno zdravstvo, pa čak i zdravstveno zakonodavstvo. Ostaci higijnsko-zdravstvenih građevina pokazuju nam i danas izuzetno visoko tehničko znanje kao i neprestanu brigu, ne samo o čoveku, već i o javnoj higijeni.
O lekarskim školama na Kosu i Rodosu obaveštava nas Galen a o školama na Krotonu i Kireni i Knidu piše nam Herodot.

Razlika između Hipokratove i Galenove medicine $^{1}$ (i naravno medicine posle njega), leži u činjenici da su u Hipokratovo vreme u lečenju bolesnika primarnu ulogu imale njegove prirodne moći , a tek potom lek. Od Galena, konsultovanje knjiga sa receptima postaje najvažniji deo lekarske prakse. Većina lekova je poticala iz udaljenih krajeva, i sadržala je sastojke koji po pravilu nisu

1 Milne, J.S., 1970, 87-88: Galen II 669 


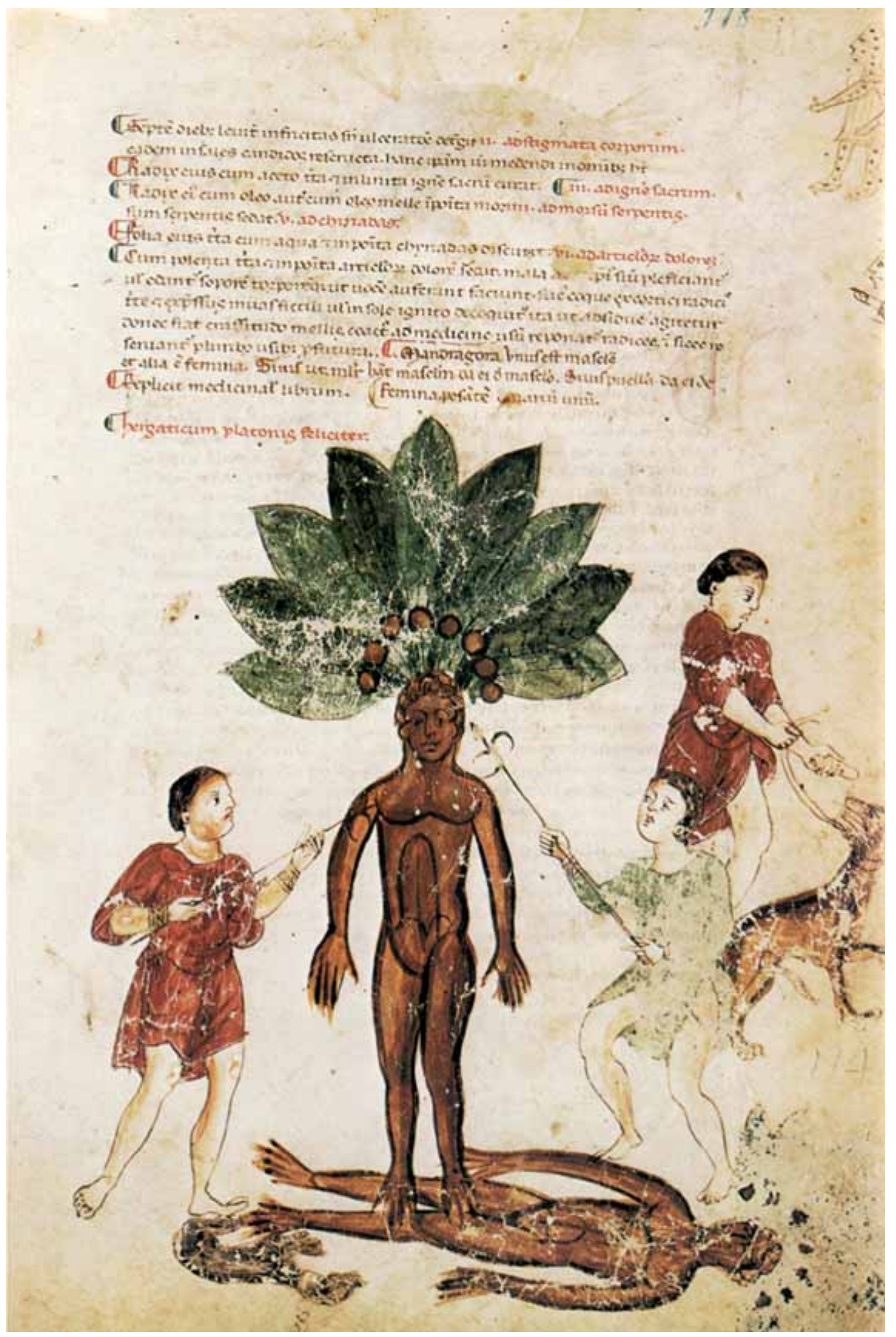

Alraunenernte (Medicina Antiqua) 


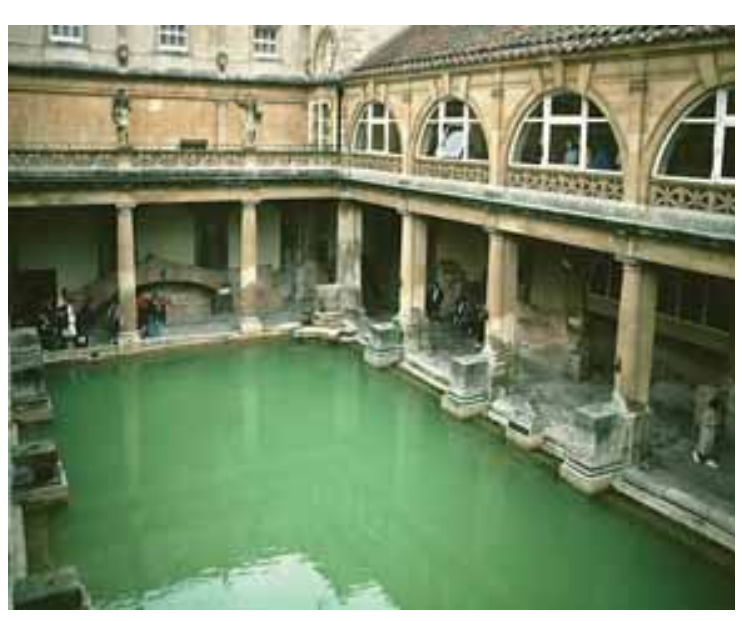

Rimske terme Bat (Velika Britanija)

postojali u mestima bolesnika, pa su se supstance teško nabavljale i bile skupe.To je svakako je imalo dodatni psihološki elemenat u lečenju bolesnika, zbog čega su lekovi bili često sa uputstvom za upotrebu i bili su pažljivo izrađeni.

Iako do danas nije ostao sačuvan dokument kojim se povtrđuju kategorizacije lekara, na osnovu izvora, a većim delom na osnovu epigrafskog materijala, moguće je uspostaviti nekakav hijerarhijski odnos među njima:

Livije pominje meddix tutius, kao ekvivalent curator publicus, Marcijal nam govori o clinicus-u i njemu nadređenome archiatrus-u.

O imperatorovom zdravlju brinuo je lekar sa titulom vir ilustris praepositus sacri cubiculi, a pod njegovom službom su archiatri sacri palatini. Poznato je da su oni na dvoru vršili carsku službu. Kako nam je ostalo zapisano u Codex-u Theodosianus-u oni imaju kroz ceo rimski period veoma važan imunitet i važan položaj kao comites primi ili secundi ordinaris.

Briga o zdravlju stanovnika glavnog grada Rima i kasnije Konstantinopolja, poverena je municipalnoj upravi. Bila je organizovana i lekarska služba za sirotinju i nju vrši 14 lekara sa titulom archiatri, po jedan za svaki deo grada. Oni imaju stalnu platu, a mesta koja oni isprazne popunjavaju se izborom. Kako nas obaveštava Svetonije, prvi put i to samo za određene ličnosti, stalnu i redovnu platu je ustanovio Vespazijan. Prvi profesor sa državnom platom je bio Kvintilijan. Kako nam piše Dion Kasije, Hadrijan je državnu platu dodelio i lekarima po većim gradovima u provincijama, kao na primer u u Aleksandriji i Atini.
U civilnim, odnosno u javnim službama susrećemo titulaciju clinicus medicus. Kod Grka je titula za lekara sofistu iatrosophiste, ujedno označavala i osobu u rangu profesora medicine .

Po Pliniju², ekvivalent za ovo u Rimu je $i a$ traleiptes, odnosno aliptes (alipta) kako nam piše Juvenal.

U javnim službama organizovana je i služba koja bi u današnjim uslovima bila najbliža pojmu patronažne službe i tu su posvedočeni circulatores, ambulantni lekari koji su posećivali bolesnike po kućama. Demosten, Hipokrat, Aleksandar iz Tralesa, Paul Aegineta ${ }^{3}$, pišu o medicus periodicus.

Seneka nam kaže, da su glavni lekari u Rimu bili Grci i on o njima govori kao o servi medici, a Svetonije piše o kućnim lekarima kao domestici et familiares medici. Naravno poznati su i lekari oslobođenici liberti medici, uglavnom robovi. Jedan od takvih je i Domitius Aheobarbus lekar-rob posvedočen 49. p. n. e.

U Livijinom columbarium-u posvedočeni su jedan lekar i jedan hirurg, oba oslobođenici.

Poznati su nam i superpositus medicorum, odnosno supra medicos sa nedovoljno jasnom funkcijom.

O javnim ambulantama kao taberna medi$c a$, piše Plaut i Aelian, ali javne ambulante kao iatreia prvi je ustanovio još Hipokrat. Veći objekti, tipa današnjih bolnica, gde su lečeni bolesnici poznati su kao Iatreion. Livije nam govori o bolnicama u Rimu, a Plinije pominje empta publice taberna. Katon će nas po prvi put obavestiti o valetudinaria, odnosno o supra valetudinarium, a o njima će pisati i Seneka i Tacit. Na jednom natpisu se pominje Alchinus supra valetudinarium.

Pojam vojna medicina, egzistira već kod Homera gde se u Ilijadi ona i pominje. Diodor pominje vojne bolnice a takođe ih pominje i Ksenofont. Kod Rimljana, koji su vojnu veštinu uzdigli do perfekcije, vojna medicina zauzima istaknuto mesto. O tome pišu Tacit, Dion iz Halikarnasa, Livije, Polibije, Onasander, Vegecije.

$\mathrm{U}$ vreme Carstva, vojni lekari kao medici ordinarii, medici legionis pominju se kao lekari koji su bili nadležni za ale ili kohorte, u svakom slučaju kao lekari koji su obavljali delatnost u okviru logora u valetudinariumima.

2 Pliny, XXIX, 16

3 Milne, J. S, 1970, 134, Pl. XLI 1: Paulus Aegineta, CMG IX 2; VI 106 
Njima nadređeni su svakao medicus castrensis i castrorum i njegov rang je kako nas obaveštava Vegecije relevantan praefectus-u castrorum-u. Iako je lečenje bolesnih vojnika svakako in hospitiis, ponekad, kao u vreme Aleksandra Severa, uslovi diktiraju da se briga o bolesnicima organizuje per tentoria, carpenta. U VI veku za vreme Mavrikija, poznate su abulance volante.

Iako su vojni lekari bili izdvojeni od civilnih, ponekad je dolazilo i do mešanja i to je bilo posebno kodifikovano (Codex Iustinianus). Na jednom natpisu osvedočen je civilni lekar salariarius civitatis splendidissimae Ferentinensium koji je službovao u alae-i Indianae i tertia Asturum. U jednoj od legija posvedočen je i civilni lekar pod imenom Kalimorphos. Galen pominje lekara po imenu Antigonos, koji je službovao za vreme Marka Aurelija i učestvovao u markomanskom ratu. Isti, pominje očnog lekara koji je službovao u floti u Bretanji.

Pod Aleksandrom Severom, lekari kao medicus palatinus, salarium su bili posebno i dodatno plaćeni kao i archiatri palatini. Njih nailazimo posvedočene u Codex-u Theodosianus- $u$ i u jednoj od Konstantinovih konstitucija kao archiatri i ex-archiatri. Moguće je da je archiatrus uveden za vreme Dioklecijana i da je predstavljao poseban atribut lekara i to veoma ekskluzivnog. Archiatri palatini u kasnoj antici su bili spectabiles comites primi $\mathrm{i}$ secundi ordinis i imali su čak i administrativnu i političku funkciju. Teodorik im je dao i veoma visoku funkciju sa titulom comes archiatrorum.

\section{ANESTEZIJA I BOL U ANTIČKO DOBA}

Plutarh opisuje operaciju koja je izvededena u II veku pre n. e. i hrabrost rimskog vojskvođe Marija: ..."Postoje dokazi o izdržljivosti i hrabrosti Marija, koje je i operacija potvrdila. Kako se čini oboleo je od proširenih vena obe noge i pošto se nije mirio sa ružnim izgledom, rešio je da se preda lekaru u ruke. Odbivši da ga vežu, a zatim bez ijedne grimase i ne puštajući od sebe ni glasa, u tišini, i sa mirnim izrazom na licu izdržao je strahoviti bol prouzrokovanu nožem. Međutim kada je lekar pristupio lečenju druge noge Marije nije želeo da dalje pati, izjavivši da izlečenje nije vredno patnje"...

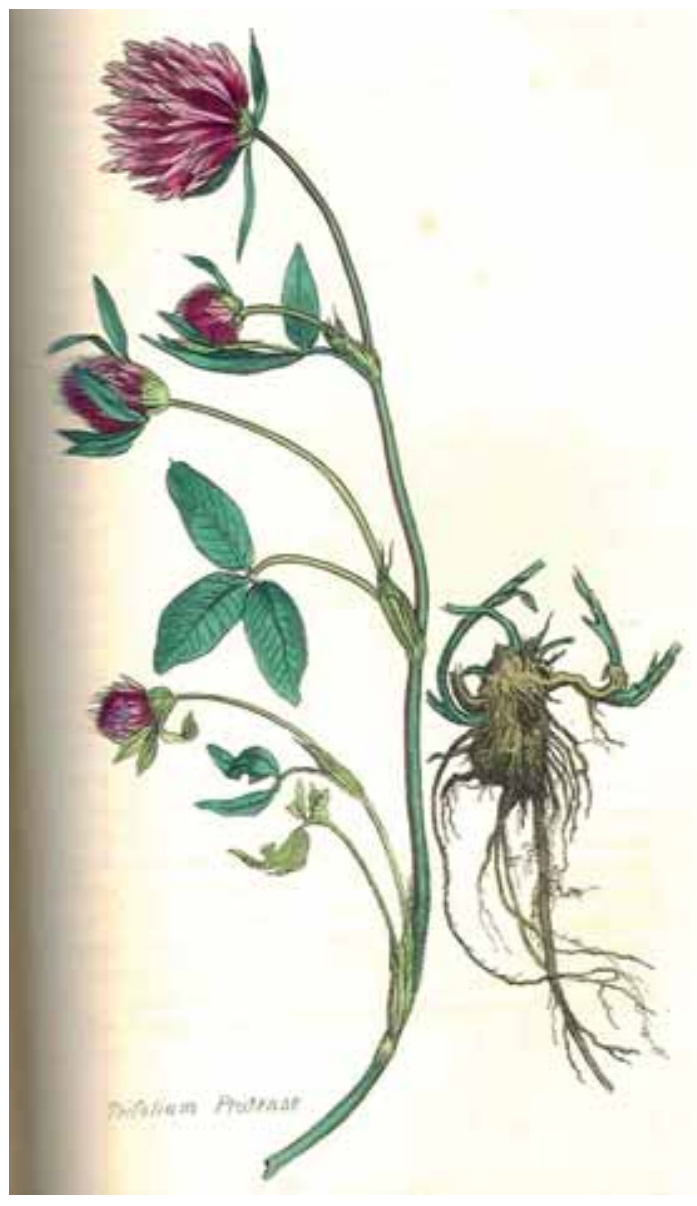

Rimski herbarijum

Zbog izuzetnih bolova koji su bili prouzrokovani operacijom, $u$ antičkom svetu postojalo je i nekoliko anestetika koji su te bolove ublažavali. Egipćani koji su veoma upražnjavali hirurške metode lečenja, poznavali su dejstvo čaure opijuma. Postoje nepobitni dokazi da je opijum bio u upotrebi u Egiptu i pre vremena XVIII dinastije (1590.-1340. g. pre n. e.). Po papirusu Edvina Smita koji potiče iz sredine XVII veka pre n. e, kao anestetičko sredstvo preporučivan je "crveni šerep", najverovatnije neka vrsta opijuma, koji je služio za ublažavanje bolova prilikom ranjavanja.

Pre nekih operacija davao se alkohol to $\mathrm{u}$ neograničenim količinama. Plinije, Diskurides ${ }^{4}$ i

4 Pedanius Dioscurides Anazarbius, 1958, V, 103; Berendes, J. 1902:1902, 48; Srpski prevod Dioskuridesovog kodeksa koji je poznat kao Hilandarski medicinski kodeks br. 517, nastao u Hilandaru u XV-XVI veku, predstavlja izuzetnost u našoj medicinskog baštini, Katić, R. 1955, 85-95; Medicina kod Srba u srednjem veku, 1958, 66-78; Hilandarski medicinski kodeks No 517, 1980. 22 


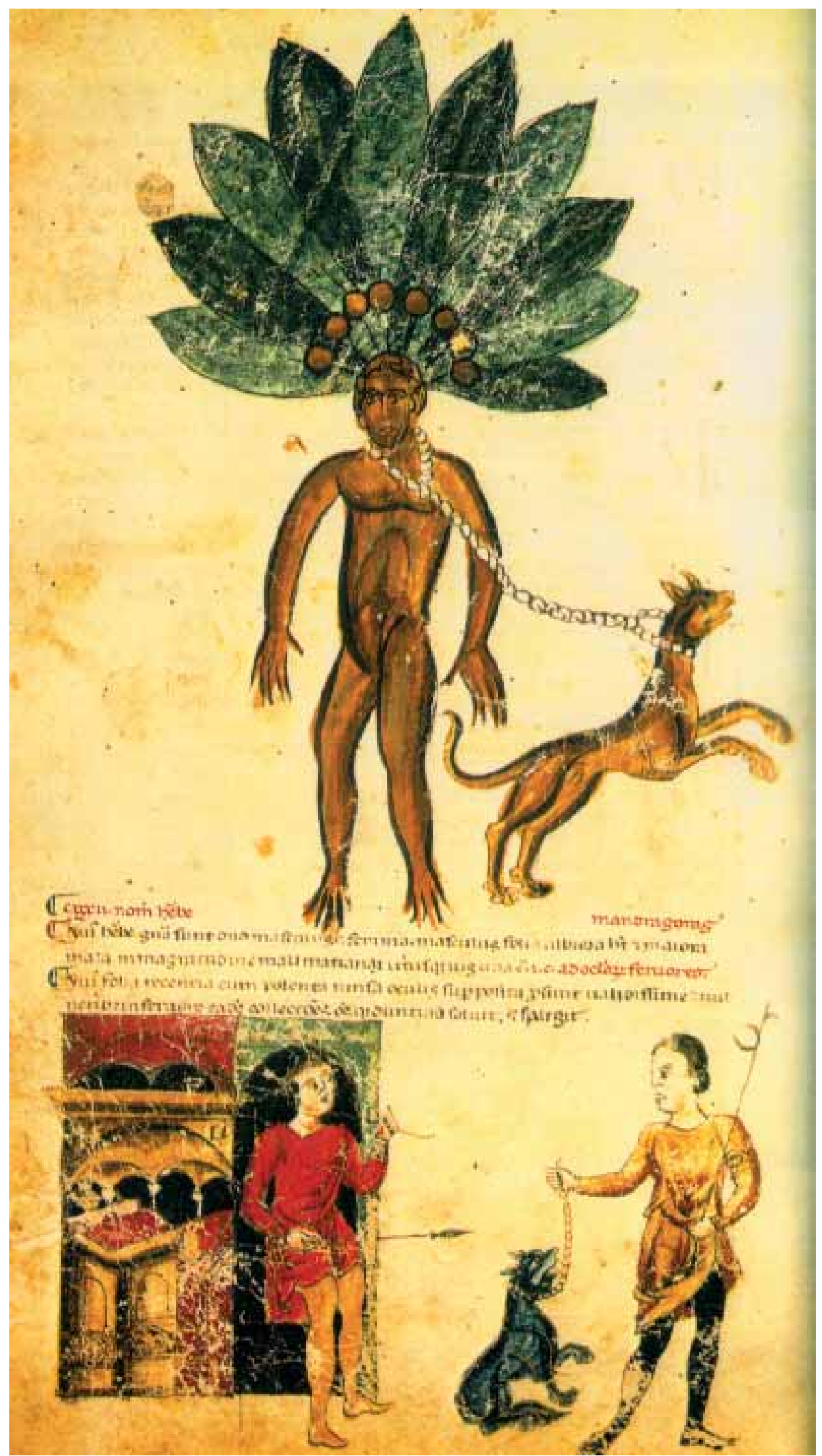

Codex Vindobonensis 93. Facsimile (Washington University, Becker Library) 
Apuleus preporučuju biljku mandragoru, za koju se danas zna da sadrži alkaloide beladone.

Metod koji su koristili asirski hirurzi prilikom obrezivanja dece je bio taj, da su ih dovodili do stanja bez svesti metodom kontrolisanog gušenja. Ovaj metod se očuvao u Italiji sve do kraja XVII veka.

U antičko doba kao anestetičko sredstvo koristio se i potres mozga, to se postizalo nimalo nežnim udaranjem maljem po glavi.

Međutim i pored neospornog napredovanja medicine, neefikasnost u suzbijanju bola prilikom intervencija na pacijentiu je bila evidentna sve do XIX veka do otkrića etarske anestezije.

\section{INFEKCIJE}

Ako se infekcija širi po površini rane oko nje se stvara crveni okvir. Grci su ovu pojavu nazivali "erizipelas". Ukoliko se infekcija proširi dublje u tkivo, dolazi do prekomerne propustljivosti krvnih sudova i rana otiče. Zbog toga što bakterije nastavljaju da osvajaju sve veći prostor, rana se pretvara u sve veći čir. Još veća komplikacija, uništavanje okolnog tkiva biloje poznato i grčkim lekarima i oni su ovo nazivali "melazmos" ili "crnilo", odnosno ono što se danas naziva gangrenom. Od tog momenta bakterije mogu da se prošire i da se nađu u bilo kom delu ljudskog tela. Ova katstrofalna posledica pod nazivom sepsa, u antičko doba je bila neizbežno smrtonosna . Sve ove manifestacije i infekcije bile su tako karakteristične kao pojave tako da su antički lekari nažalost pogrešno verovali da svaka od ovih faza predstavlja posebno i različito oboljenje. Posledica takvog načina razmišljanja bila je ta da da su smatrali da pojava gnoja nije uvek loš znak. Grčki lekari su smatrali da je stvaranje beličastog gnoja koji nema miris čak veoma povoljan znak toka bolesti, pa su čak i činili sve da podstaknu njegovo stvaranje, što je često imalo tragične posledice.

Tek mnogo vekova kasnije pronalaskom antibiotika mogućnost šanse za izlečenje će se znatno povećati.

\section{LEKOVI, MELEMI I PARAPASTAE}

Theriaci - pastile od životinjskog mesa Plinije napominje da Grci prave pastile od zmijskog mesa. Ježevo meso, osušeno i pomešano sa zakiseljenim medom - za bubrege i tzv. vodenu bolest. Pepeo raka se preporučuje protiv besnila pasa. Zmijska koža se preporučuje protiv infekcije ušiju i za ispiranje usta kod zubobolje. Od zeca je korišćen mozak i krv, od sipe meso i kost (ossa sepia), dabrovina (castoreum) je korišćena za unutrašnju upotrebu a spaljene žabe (životinjski ugalj) protiv krvarenja. Osušena ptičja pluća su bila blagotvorna protiv astme a magareća jetra protiv epilepsije, dok su testisi od jelena bili spasonosni ukoliko dođe do zmijskog uboda. Jetra divlje svinje, koze i magareće(vo) kopito navodi se kao lek. Slonovača se upotrebljavala u opiljcima kao i spaljeni jelenji rogovi a utvrđeno je da oboje sadrže kalcijum fosfat. Želatin je pravljen iz kože goveda i upotrebljavan je za rane i opekotine. Konj, jarac, ovca, jelen, zec, gazela, srna, tele, morski pas ' - takođe su upotrebljavani za spravljanje lekova. Dioskurid pominje i mast domaćih i divljih životinja, od kokoške, svinje, medveda, koze, ovce, jelena, goveda, pantera, slona, magarca, lisice, raznih riba i zmija, mozak jelena, koze, ovce, žuč raznih riba, kornjače, jarebice, orla. Žuč goveda se i danas upotrebljava kao lek.

Sledbenici Hipokratove škole su upotrebljavali svežu ostriženu vunu za obloge i povijanje rana. Dioskurid umesto današnjeg pamuka, upotrebljava vučju vunu namočenu sa vinskim "sirćetom". Iz ovčje vune dobijana je mast (lanolin).

Lekari su lekove sami spravljali. Ponekad su se upoznavali sa biljnim i životinjskim materijama, zatim ih sakupljali i na kraju od njih spravljali lekove. Poneki od njih su kupovali bilje od sakupljača i prodavaca bilja.

Lekari su sa sobom nosili svoje priručne apoteke i svoj medicinski instrumentarij koji je bio smešten u bronzanim kutijicama ili u kutijicama od slonovače ali i u drvenim ormarićima. Kutije ili ormarići su često bili ukrašeni reljefnim predstavama Eskulapa ili Higije. Galen skreće pažnju na tačne težinske odnose, a propisivao je i preciznu težinu. Galenova libra, odnosno funta sadržala je tačno 12 uncija. Ovaj težinski odnos se u farmakologiji održao sve do 19 . veka. Galen je prvi lekar koji je sastavio popis alternativ- 
nih sastojaka koji mogu da se upotrebe prilikom sparavljanja lekova naričito usled veće potrošnje lekova prilikom epidemija. Galen je prilikom dijagnoze uzimao u obzir i pregled mokraće. Njegova jednostavnost i delotvornost u pripremanju lekova održala se sve do XIX veka. Ovi lekovi u farmakologiji su poznati kao "Galenovi lekovi”. Njegov način pripremanja lekova se održao punih 14 vekova sve do XV veka. Praktično Galen je u farmakologiji pa i u medicini ostao neprikosnoven sve do pojave Paracelza.

\section{RAZVOJ MEDICINE KOD RIMLJANA}

Početak razvoja medicine u Rimu vezuje se za početak III veka pre n.e. Do tog vremena na ovom prostoru osim božanskih zaštita koje su Rimljane štitile od zamki koje im je priroda postavljala, negovan je poseban empirisjki način isceljenja bolesnika, utkan u magijsko-verska obeležja. U rano republikansko doba, po nekima do 293. godine negovan je samo kult Apolona koji je imao i funkciju isceljenja, a od 293.odnosno 291. godine (vreme pogubne kuge koja je harala Rimom početkom III veka pre n.e.) uveden i kult Asklepija, inače Apolonovog sina.

Najčuvenije svetilište kulta Asklepija je bilo u Epidauru u Argolidi. Godine 291. nakon strašne kuge koja je zadesila Rim na Tibarskom ostrvu je podignut hram povećen bogu Eskulapu. Iako uvođenjem Asklepijevog odnosno Eskulapovog kulta u shvatanjima Rimljanja u pogledu medicine nije ništa bitnije promenjeno (naime ona je i dalje imala kao osnovu magijsko-verski i empirijski karakter), ipak je, doduše na posredan način, počela da se razvija rimska medicina. U ovom razvoju medicine kod Rimljana dolaziće u nekim periodima, recimo pod Markom Porcijem Katonon (234-149. pre n. e.) i do plime uticaja pradedovskih tradicija oslonjenih na narodnu medicinu koja se u dugom periodu oslanjala manje-više na botanička iskustva a u nekim slučajevima i na primitivna hirurška iskustva u isceljenju obolelog, kao i na sadejstvu prirodnih procesa u ljudskom organizmu ${ }^{5}$.

Veoma je interesantno da iako je u Rimu bilo više uglednih lekara, doduše iz Grčke i Male

5 Pliny, XXIX, 14
Azije, a neki od njih su bili ugledni i cenjeni dvorski lekari, medicinska nauka kao organizovana tvorevina državnog tipa nije postojala do Vespazijana, odnosno do osnivanja Ateneuma (Athenaeum). U ovom hramu nauke osim ostalih predavanja iz retorike, filozofije i prava, najcenjenijih u rimskom obrazovanju, održavani su i časovi iz medicinske nauke. Ovi časovi koji su kao i u drugim veštinama bili javnog karaktera i slobodni za pristup, finansirala je Rimska država, angažujući najbolje učitelje iz Grčke i iz Male Azije.

Nepostojanje rimske medicinske škole kakve su postojale u Grčkoj i maloj Aziji, svakako ne isključuje postojanje nastave i određenih kurseva koji su se održavali na slobodno rečeno univerzitetskim školama ili postojanje brojnih lekara od kojih su neki obavljali praksu i u ambulantama (tabernae medicae).

\section{PODELA MEDICINE}

Antička medicina je obuhvatala više oblasti:

1) Hirurgija - najstarija medicinska disciplina u antičkoj Grčkoj. Hipokratovi spisi pokazuju da je anatomija kao jedna od osnova hirurgije bila visoko razvijena.. Sprovodile su se komplikovane operacije sa specijalizovanim medicinskim instrumentarijem. Lekar koji se posebno isticao u specijalizovanim operacijama bio je jedan iz plejade izuzetnih lekara antike -Antylos.

2) Dijetetika - druga oblast medicine koja je bila razvijena u antici je nauka o poboljšanju načina života (uključujući i higijenu i gimnastiku) i ona se razvijala kao posebna grana medicine. U okviru dijetetike izdvajale su se i dve posebne potdiscipline, fizikalna medicina i terapija i njeni najpoznatiji predstavnik je bio Diokle iz Kariste. Ona su imale posebno i istaknuto mesto i okviru Hipokratovog poimanja medicine, a posebno pojedinih grana pneumatske škole i Galena.

3) Anatomija - Anatomija bila je naročito razvijena u Aleksandriji, a njeni najpoznatiji predstavnici te škole su lekari Ruf i Galen. Ova škola provodila je ekperimente sa utvrđivanjima zdravstvenog stanja pacijenta na osnovu njegovog pulsa

4) Fiziologija je manje-više bila u sferi spekulativno filozofskih postavki sa istaknutim lekarima Hipokratom, Asklepijadom iz Pruse, kao I pojedinim metodičarima i empiričarima. 
5) Farmakologija - na farmakološkom polju najpoznatiji su lekari Knidske medicinske škole. U IVveku pre n. e., pojavili su se i prvi priručnici za lekove. Primer za to je priručnik koji je sastavio Diokle iz Kariste. Svakako treba pomenuti i prvi botanički vodič koji je sastavio Teofrastos, pravi predstavnik empiričke lekarske škole. U Rimskom carstvu magijsko-religijska komponenta postaje sekundarna i sve je veća upotreba primena i spravljanje lekova na bazi organskih (životinje i biljke ) i neorgamnskih (minerali) materija. Dragocene podatke o tome daje nam najpoznatija knjiga iz farmakologije Diskoridova

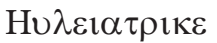

6) Ginekologija - je jedna od grana medicine koja je imala najpraktičniju osnovu. Jedna od naznačajnih je bila Aleksandrijska medicinska škola sa predstavnicima Herofiilosom i Eudemosom. Ipak najznačajniji lekar koji se bavio ginekologijom bio je učeni Soran iz Efesa koji je radio na prelazu iz I u II vek.

7) Oftalmologija - praktično počinje da se razvija od sredine I veka pre n. e. od Cezara, kada se za ovu vrstu lekara koristi izraz medici ocularii. Poznato je da je po Neronovoj naredbi napisan udžbenik iz oftalmologije koji nažalost nije sačuvan. U Carsko doba već postoje utemeljeni pojedini kolegijumi lekara, kao na primer kolegiji očnih lekara.

Medicinu su Grci delili na:

1. diaitetike

2. farmakeutike $\mathrm{i}$

3. cheirurgike

Treba reći da je u lekarskoj terminologiji podjednako korišćen grčki i latinki jezik. Na osnovu sačuvanih rukopisa, latinski jezik je preovalađujući u anatomiji, a grčki u patologiji.

\section{BIBLIOGRAFIJA}

\section{Celsus, 1961}

Celsus, De Medicina, translated by W. G. Spencer, The Loeb Classical Library (LCL), Cambridge-Massachusetts 1961, 3 vols., V,17

\section{Pliny, 1967-1971}

Pliny, Naturalis History, Translated by H. Rackam, D. E. Eicholz, W. H. S. Jones, LCL, 10 vols., Cambridge-Massachusetts 1967-1971.

Pedanius Dioscurides Anazarbius, 1958

Pedanius Dioscurides Anazarbius, De materia medica, hrsg. v. M. Wellman, Bd. I-III, 2 Aufl., Berlin 1958

\section{Berendes, J. 1902}

Berendes, J. 1902. Des Pedanios Dioskurides Aezneimittellehre (Materia Medica), Stuttgart 1902, 48

Katić, R. 1955

Katić, R, 1955, Srpski prevod Dioskuridesovog kodeksa nadragoceniji spomenik naše medicinske kulture,

Medicina kod Srba u srednjem veku, 1958

Medicina kod Srba u srednjem veku, Srpska Akademija nauka, Poseb. Izd. Knj. CCCX, Odeljenje medicinskih nauka, Knj. 12. Beograd 1958, 66-78;

Hilandarski medicinski kodeks $\mathbf{N}^{0}$ 517, 1980

Hilandarski medicinski kodeks $\mathrm{N}^{\circ} 517$, 1980, Narodna biblioteka Srbije, Beograd 1980.

Milne, J. S., 1970

Milne, J. S., 1970, Surgical Instruments in Greek and Roman Times, Mecina Classica, London 1907 (Reprint 1970) New York 1970, Pl. LIII 


\section{SOME ASPECTS OF ANCIENT MEDICINE}

The paper gives a brief overview of some aspects of ancient medicine. The ancient writers, Greek and Roman, epigraph monuments and papyrus (Papyrus Ebers, and others) are valuable documents that testify about. Caring for the health of the population was at high level and traditional medicine has existed in parallel with the professional doctor. In the cities there were pharmacies where they bought drugs from many distant parts of the Roman Empire. Concern about the health of residents of the capital Rome and later Constantinople, was entrusted to the municipal administration. Although military doctors have been separated from civil, and sometimes came to mixing and it was specifically codified (Codex Iustinianus). In the Roman Empire there were no schools, as was the case in Greece or Asia Minor coast. Ancient medicine was divided into several areas: 1) Surgery 2) Dietetics 3) Anatomy 4) Physiology 5) Pharmacology 6) Gynecology and 7) Ophthalmology.

KeY WORDS: RoMAn MEDICINE, GREEK MEDICINE, Galen, Diokurid, Hippocrates, Plutarch, DioDORUS, XENOPHON, INFECTIONS, BALMS, MEDICINES, PARAPSTAE, Codex IUSTINIANUS 

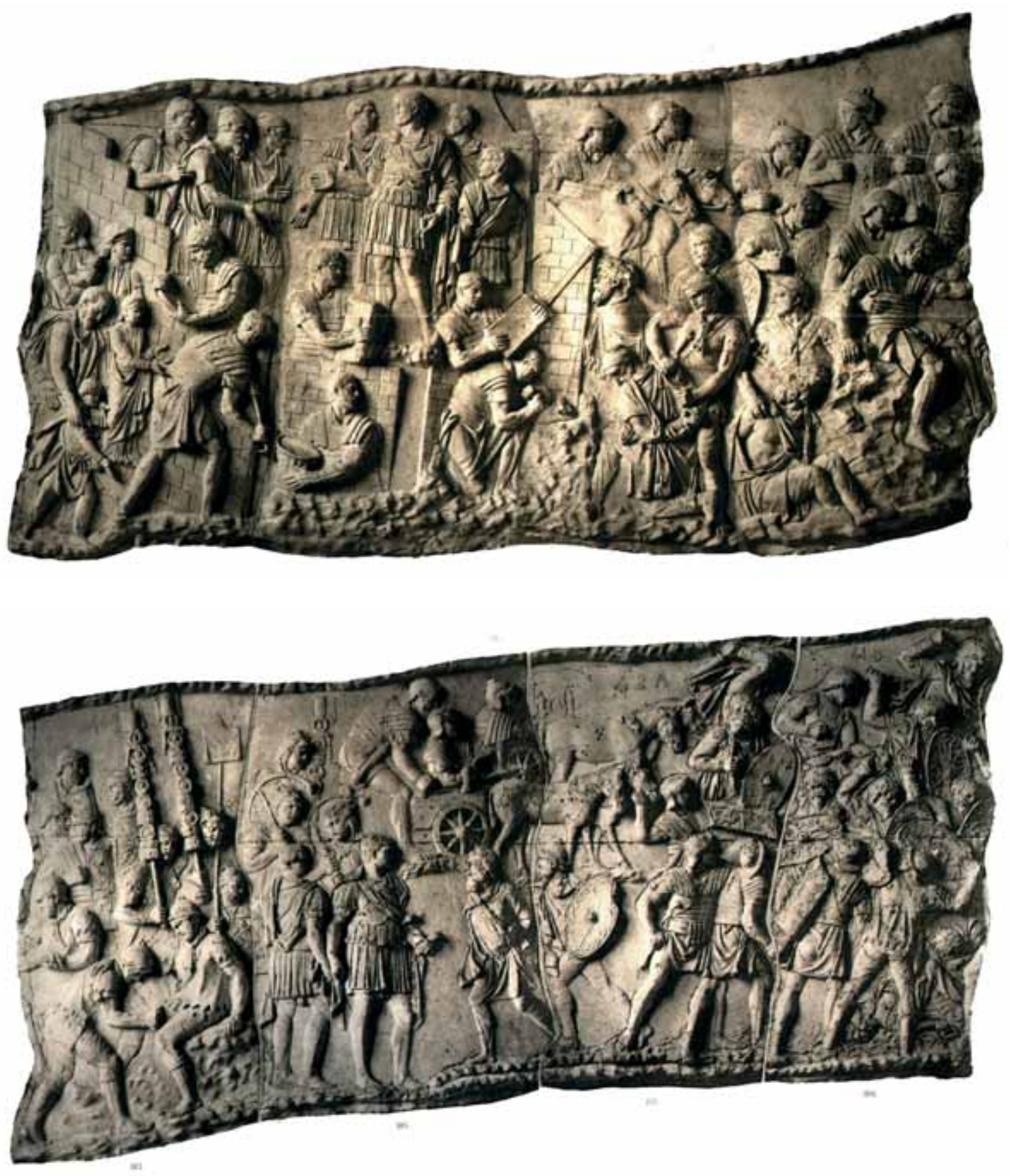

Trajanov stub predstava lekarske intervencije 